\title{
Nanogram per Kilogram
}

National Cancer Institute

\section{Source}

National Cancer Institute. Nanogram per Kilogram. NCI Thesaurus. Code C67429.

A unit of mass fraction expressed as a number of nanograms of a substance per

kilogram of the mixture. The unit is also used as a dose calculation unit. 